\title{
Study the iron environments of the steel waste product and its possible potential applications in ferrites
}

\begin{abstract}
In this project, the permanent magnets ferrites have been prepared by recycle the steel waste product. Steel waste is an impure material that contains the iron oxides and impurities. The steel waste product is a form of flakes is grinding for several hours to form a fine powder. The iron oxides powders are separated from magnetic and non-magnetic particle using magnetic particle separation. The magnetic particles was again been purified by using the Curie temperature separation. The magnetic powder carried out from the purification was heated at $500{ }^{\circ} \mathrm{C}$ for 6 hours at $6{ }^{\circ} \mathrm{C} /$ mins to form hematite, $\mathrm{Fe}_{2} \mathrm{O}_{3}$. The constitute amount of $\mathrm{BaCO}_{3}$ and $\mathrm{Fe}_{2} \mathrm{O}_{3}$ derived by steel waste product are mixed by using mechanical alloying to prepare the barium hexaferrites $\left(\mathrm{BaFe}_{12} \mathrm{O}_{19}\right)$. The samples were sintered at different temperature $600 / 800 / 1000 / 1200{ }^{\circ} \mathrm{C}$ for 6 hours at $6{ }^{\circ} \mathrm{C} /$ mins. The composition of $\mathrm{FeO}, \mathrm{Fe}_{3} \mathrm{O}_{4}$ and $\mathrm{Fe}_{2} \mathrm{O}_{3}$ of the steel waste product was carried out using X-ray Fluorescence (XRF) and Energy Dispersive Spectroscopy (EDAX). The crystallography of sample is observed by using X-ray Diffraction (XRD). Microstructure of samples was carried out by using Field Emission Scanning Electron Microscope (FESEM) and Atomic Force Microscopy (AFM). The saturation magnetization, Curie temperature and density are also observed. The results show the purification process yields high purity of hematite, $\mathrm{Fe}_{2} \mathrm{O}_{3}$. The common characteristics of the steel waste product are its low cost, availability and thus the potential for large production volumes, need for recycling, and tendency to further oxidation in the production of ferrites.
\end{abstract}

Keyword: $\mathrm{FeO} ; \mathrm{Fe} 3 \mathrm{O} 4 ; \mathrm{Fe} 2 \mathrm{O} 3 ; \mathrm{BaFe} 12 \mathrm{O} 19$ 